\title{
Um Encontro com Pinocchio - Arte e Vida na Escola
}

\author{
A Meeting with Pinocchio - Art and Life at School \\ Un Encuentro con Pinocchio - El Arte y la Vida en la Escuela
}

\section{Katia Faria de Aguiar}

Universidade Federal Fluminense, Niteroi, RJ, Brasil.

\section{Vanessa Monteiro Silva}

Universidade Federal Fluminense, Niteroi, RJ, Brasil.

\section{Resumo}

Neste ensaio, propomos uma conexão crítica entre o território escolar e o filme Pinocchio, de Roberto Begnini (2002), escolhido por trazer uma versão cômica do conto original As Aventuras de Pinocchio, de Carlo Collodi. Afirmando a entrada micropolítica através de relações entre nossa própria prática e os personagens do filme, trazemos a potência do cômico na interpelação de situações-problema, abalando as forças que comprimem a vida nos limites do que deve ser. Pensamos, então, os signos de resistência que emergem dos encontros entre alunos travessos e as pequenas mortificações sob forma de conservadorismos morais que atravessam o cotidiano escolar e nossas intervenções. Desse modo, emprestamos nossos corpos para dar passagem às tensões paradoxais, acolhendo deslocamentos que nos forçam a pensar e fortalecem a potência inventiva, provocando, enfim, novos sentidos para os encontros entre práticas educativas e meninos travessos.

Palavras-chave: Psicologia; Escola; Subjetividades; Estética

\begin{abstract}
In this paper, we suggest a critic connection between the school territory and Roberto Begnini's movie Pinocchio (2002), chosen for its comic version of the original tale "The Adventures of Pinocchio", from Carlo Collodi. Postulating a micropolitic entry through the relation of our practices and the movie characters, we bring the comic potency in the interpretation of problematic situations, shaking the forces that oblige life in limits of what should be. Therefore, we think about the resistance signs that emerge from the encounter of wilful students and the little mortifications of the moral traditions that compose the day-to-day scholar routine and ours interventions. This way, we offer our bodies as a way of passage of paradox tensions, giving space
\end{abstract}


to movements that compel to think and strengthen the creative force, finally stimulating new senses for the encounters between educational practices and willful boys.

Key words: Psychology; School; Subjectivities; Aesthetics

\section{Resumen}

En el presente ensayo nos proponemos una conexión crítica entre el territorio escolar y la película Pinocho, de Roberto Begnini (2002), elegida por traer una versión cómica del cuento original Pinocho, de Carlo Collodi. Afirmando la entrada micropolítica a través de las relaciones entre nuestra propia práctica y los personajes de la película, traemos la potencia de lo cómico en la interpelación de situaciones-problema, abalando las fuerzas que comprimen la vida en los límites de lo que debe ser. Pensamos, entonces, los signos de resistencia que emergen de los encuentros entre los alumnos traviesos y las pequeñas mortificaciones sobre la forma de conservadorismos morales que atraviesan el cotidiano escolar y nuestras intervenciones. De este modo, prestamos nuestros cuerpos para dar pasaje a las tensiones paradojales, acogiendo desplazamientos que nos fuerzan a pensar y fortalecen la potencia inventiva, provocando, en fin, nuevos sentidos para los encuentros entre prácticas educativas y niños traviesos.

Palabras claves: Psicología, Escuela, Subjetividades, Estética.

“não há método para encontrar tesouros nem para aprender"

G.Deleuze

Pensar nos termos da implicação com a história das práticas que fazem de nós o que somos e, nesse exercício de problematização, manter em questão a produção de um horizonte libertário, exige um trabalho sobre nós mesmos. Um trabalho de análise crítica, em ato, das relações de domínio sobre as coisas (saberes), das relações de ação sobre os outros (poderes) e das reRev. Polis e Psique, 2013;3(2):97-112 lações de cada um consigo mesmo (éticas), colocado por Foucault (2000) como condição para constituir-nos a nós mesmos como sujeitos autônomos, portadores de um ethos.

É com esse desafio e nesse horizonte que temos nos ocupado, de diferentes maneiras e por diferentes entradas, da formação de psicólogos. Uma empreitada que entendemos como arriscada, considerando as tensões paradoxais que habitam as práticas psis em suas implicações com a denominada cultura ocidental, com a qual fazemos aqui referência aos processos de constituição histórica de nossa subjetividade. 
Entendemos que somos habitantes desse mundo e é nele, com ele e apesar dele, que forjamos os lugares que ocupamos e um modo de habitá-los. Aposta política que exige, dentre outros investimentos, interpelar a pretensa garantia de estabilidade que justifica a crença nas tradições e as idealizações que nos arrastam para um plano transcendente, nos instalando em totalitarismos.

Estar em meio às práticas de formação com profissionais e estudantes de psicologia nos convida a colocar em análise a dimensão conservadora dessas práticas liberando saberes e fazeres menores e favorecendo a abertura ao plural, à variabilidade que se espreita na dimensão rotineira, sempre mais visível, do cotidiano. Para tanto, nos diferentes territórios que compõem a formação como campo de análise e de intervenção (aulas, pesquisa, estudos, extensão, estágios, etc.), nossa atenção se coloca nos processos disparados por diferentes dispositivos tomando-os como fonte de recursos materiais e imateriais que alimentam nosso trabalho.

Nos processos, estamos interessadas em localizar pontos de estrangulamento, de estancamento, de cristalizações, que bloqueiam o movimento. Prudência na fala e nos gestos, oferta de sustentação para o descarte de motivações emocionais, representacionais e expressivas (Gil, 2000) e para a criação de um plano de consistência que favoreça a virtualização, desestabilizando os instituídos, e a atualização de outros possíveis (Lévy, 1996). Nessa entrada micropolítica, iluminando a complexidade e as misturas, emprestamos nossos corpos para dar passagem àquelas tensões paradoxais, acolhendo deslocamentos que nos forçam a pensar. Essa atitude ético-estética nos implica com a recusa de aceitar as coisas como elas são e nos aproxima de uma noção de liberdade remetida ao exercício permanente da experimentação, germinando sentidos (Rocha \& Aguiar 2010; Aguiar 2003).

É nessa perspectiva que as artes se oferecem a nós como potentes intercessores a agenciar devires que escapam dos possíveis constrangimentos do que está posto como modelo vigente e, ao mesmo tempo, a oferecer linhas que favorecem desenhos outros, novas formas, frente aos riscos dos desmanchamentos na dispersão. O encontro com a arte se faz por conexão crítica, por acoplamento que, criando uma zona de indeterminação, abre acesso a variações, a experimentações que escapam das potências fixas, inventando trajetórias. É que, "à sua maneira, a arte diz o que dizem as crianças" (Deleuze, 1996, p.95).

Dos diálogos desdobrados com a literatura e o cinema, extraímos e apresentamos um fragmento desse exercício micropolítico. Propomos uma conexão crítica entre o território escolar e o filme Pinocchio, 
dirigido e interpretado por Roberto Begnini (2002), a partir da fábula As Aventuras de Pinocchio escrita em 1882, pelo italiano Carlo Collodi. Essa iniciativa encontra motivação em ocorrências escolares nas quais apreendemos signos de resistência em meio às pequenas e insistentes mortificações no cotidiano. Se entre as forças das tradições disciplinares e as forças das acelerações produtivistas a variabilidade da vida tende a esvanecer, cabe buscarmos dispositivos que favoreçam a abertura dos processos à dimensão inventiva. É para colocar em análise um pouco do que vivemos que recorremos ao filme.

Benigni nos apresenta um personagem travesso e quase trapalhão: o que se vê, nas telas, é meninice - experiências de um corpo desengonçado, por entre curiosidades e inocências, de um menino recém-criado a partir de um pedaço de tronco, a sugerir ambiguidades ao texto. A principal questão do filme, que disparou em nós as articulações com a escola e que marca a diferença com relação ao conto original, é que a moral da estória não prevalece: prevalece o modo intempestivo de ser criança - o inusitado da vida - misturado à comicidade que faz valer o que há de potente ou não para um corpo em formação.

Apesar de ter sido recebido como o pior filme daquele ano, sob a crítica de não apresentar questões dramatúrgicas elaboraRev. Polis e Psique, 2013;3(2):97-112 das e trair o texto original, entendemos que este filme guarda uma intensidade invisibilizada pela vontade cinematográfica por grandes dramas - a potência do cômico. Um dos ataques feitos se referia ao fato de um adulto de carne e osso fazer o papel do boneco da fábula, julgando essa escolha como imprópria e grotesca. No entanto, a reforçar nossa visada sobre a experiência desdobrada do encontro com a obra, Bakhtin (1996) destaca que a caricatura, numa associação entre o disforme e o cômico, se ofereceu como um elemento de resistência frente aos padrões estéticos do Iluminismo. A comicidade, como arte de fazer rir sem criticar, se dá por uma dupla e simultânea leitura que une lógica e absurdo, utilizando diferentes recursos. Dentre eles, a narrativa disjunta que, operando por desvios, estabelece cortes bifurcantes com o que está estabelecido e deve ser considerado "sério" (Morrin, 1976).

Nossa escolha pela comicidade quer afirmar a potência do gênero na interpelação de situações, comportamentos e sensações, abalando as forças que comprimem a vida nos limites do que deve ser, abrindo fissuras e favorecendo as forças de criação.

A interpretação de Benigni, embora pouco popular, remete o pensamento às vozes que narram alunos-problema que frequentam e que evadem a escola: meninos e meninas agitados, desobedientes, que pare- 
cem não conhecer as dimensões e a força de seus corpos, às vezes agressivos e sempre mal comportados, preguiçosos, incapazes, com dificuldades de aprender. Quase sempre, um pouco de tudo isso...

É no cotidiano da vida escolar, apesar de as punições por 'brincadeira fora de hora' e por 'riso sem motivo' terem se tornado procedimentos frequentes, que outros movimentos nos convidam a circular entre travessuras e meninos travessos. Com eles acompanhamos rupturas e descontinuidades nas práticas de produção de destino, interrogamos em nós as lições (morais) e o didatismo como forças de conservação e construímos dispositivos que fazem proliferar histórias de vida.

\section{Era uma vez um artesão}

O velho artesão esculpe, de um pedaço de tronco cuja forma é rígida e reta, traços e retoques de outro molde qualquer. No toque entre suas mãos e o tronco, sente as texturas que a madeira comporta. Talha, parte por parte, minuciosamente, curvas e diagonais: reforma, esculpindo um molde que se transforma e cria em si derivações, marcando braços e pernas, nariz e boca.

O artesão se demora, contempla sua obra em processo de criação e percebe que algo como um desassossego não deixa seu corpo dormir. Um desassossego inventivo
(Pessoa 2006) que atravessa seu corpo desmanchando e remontando ideias, perceptos e afetos, como um acontecimento (Deleuze \& Guattari, 2007): desassossego como dispositivo que cria rupturas naquilo que se torna natural. Passa noites e dias inteiros dedicando seu tempo, corpo e sonho ao pedaço de tronco que deixa, aos poucos, de ser apenas tronco. Para, pensa, retoma, deixa de pensar; flui, mergulhado em um movimento de se dar conta e perder a conta. Observa de perto, de longe, de outros ângulos. No corpo acordado e tomado por uma força sem nome, pensamentos se aceleram, tal como o movimento de seus dedos segurando a espátula. Revira, remexe, refaz aqui e ali.

O artesão e sua obra não são corpos quaisquer: são corpos que despertam por ímpeto de despertar. O tronco-forma des-forma e reforma, dando consistência a um menino-madeira que comporta, agora, texturas antes impensadas, ao mesmo tempo em que o artesão se reinventa como criador.

Gepetto, em sua marcenaria diária, talhou Pinocchio em meio ao sonhar. Deu-lhe um nome, deu-lhe cuidado, permitiu a condição de tornar possível o impossível. Pinocchio, antes de madeira, fora manejado, posto que feito com as mãos, e logo ganhou vida através dos poderes de uma Fada Azul que tornou real o que estava em vias de se fazer. De onde, pois, a vida surgiu, senão do próprio ato do artesão de sonhar, 
brincar, explorar e arriscar o material bruto que tinha?

Era uma vez um artesão que vivia só, em uma cidadela italiana. Era uma vez um menino. Ou seria um tronco? Uma fada azul, talvez? Por onde se pode começar a estória? Era uma vez um artesão, uma árvore e um menino em sonho.

\section{Era uma vez um menino}

Do tronco, tornado menino travesso, Pinocchio também se arrisca. Menino inquieto, desassossegado, salta, corre pelos lados, explora seus movimentos por dentro do traje cômico, tagarela sem parar. Não obedece às regras estipuladas pelo pai, deixa de ir à escola, quase se transforma em burro por se deixar guiar pelo impulso, faz promessas que não cumpre, ganha um nariz que estica quando mente, tropeça nas palavras e pelo caminho, com seu jeito desengonçado. Arrisca-se e, neste processo, arrisca seu próprio pai que o havia arriscado enquanto era, ainda, tronco: agora estão ambos dentro da barriga de uma baleia, onde se reencontram, enfim, embaralhados em suas saudades, em suas tristezas, em suas vergonhas e em suas escolhas. Dentro da barriga da baleia, tornam possível recriar suas relações de pai com filho e de menino com mundo, inventando juntos uma forma de retornar ao mar.

Rev. Polis e Psique, 2013; 3(2):97-112
É, enfim, no experimentar dos riscos, impasses e efeitos do que viu e fez acontecer que Pinocchio cria para si uma atenção às dimensões daquilo que seu corpo pode. E é, então, entre os conselhos de um Grilo Falante e o encontro com uma Fada Azul que Pinocchio se re-inventa como "um menino de verdade". Essa perspectiva da estória tem diferenças entre o texto original e o filme selecionado aqui para análise. Enquanto na linguagem do conto original, "menino-de-verdade" remete ao momento em que Pinocchio se arrepende de seus erros e pode se tornar finalmente humano, no filme não há essa dissociação moralista. Com Benigni (2006), Pinocchio é "de verdade" a partir do momento em que se torna vida, desde o momento em que Gepetto compõe sua obra. Pinocchio, quando feito, já não era de madeira, e sim de pele. Era já menino em formação, criando referências a partir daquilo que vivia em meio aos seus disparates. Um "menino de verdade" que se inventou do tronco e se re-inventou na vida, corpo-mundo em movimento nascente. Tal movimento convoca a acolher e construir um corpo digno dos acontecimentos, conforme nos aponta Deleuze, a partir de inspirações nietzscheanas: Querer o acontecimento é tornar-se digno daquilo que nos ocorre, por conseguinte, querer e capturar o acontecimento, tornar-se o filho de seus próprios acontecimentos e por ai renascer, 
refazer para si mesmo um nascimento, romper com seu nascimento de carne (Deleuze, 1982,p.152).

O que está em jogo nesta constituição de um corpo para si, é, portanto, uma composição de forças que se dobram em experiências e afetos, rumores expressivos (Fonseca \& Thomazoni, 2011) que reverberam em uma vida por se fazer. Uma vida que se apresenta como vibração intensiva de forças no encontro com um corpo; vida como processos de variação no tempo, no espaço, no mundo, no pensamento, nos possíveis; vida como multiplicidade aberta ao acaso, ao devir. Implica, portanto, estar aberto à experimentação, ao que pode desterritorializar, desestabilizar o que está consolidado (Deleuze \& Guattari 2007, 1997). Criam-se, como efeito, movimentos de reterritorialização - invenção de outros territórios ainda que provisórios - estendidos a uma série de agenciamentos que subjetivam, que constroem um sistema discursivo constituído por determinadas práticas hegemonizadas, por uma série de investimentos empregados a partir de determinada lógica e, enfim, por apropriações de tempo, espaço, pensamentos e corpos.

A invenção de outros possíveis convoca à elaboração da experiência, na experimentação da vida em meio à regularidade e irregularidade, em meio ao movimento que não se prende às formas fixas e não se esvai em constante devaneio. Se a vida é efeito de composição e decomposição de forças (Deleuze \& Guattari, 2007), encontros e agenciamentos de potências entre os corpos, então vale gerir e experimentar essa dimensão de reconstrução a todo o tempo. Reconstrução no sossego, no desassossego, na mistura.

Pinocchio, como todo menino, como todo menino de verdade, brinca, experimenta, se diverte, se demora, se perde, se mistura, é assim que sente a vida; é assim que aprende a fazer potente a vida que tem. Spinoza (2008) nos inspira a pensar que o corpo é a superfície onde acontecem os encontros, sendo, portanto, ali mesmo o espaço de aprendizado, a partir da experiência sensível de afetação que pode potencializar ou fazer padecer. Concebendo junto à Spinoza uma relação imediata entre corpo e pensamento, observamos que, em sua experiência travessa de um menino feito de madeira, $\mathrm{Pi}$ nocchio exercita pensamentos autônomos, indagando a vida que quer construir para si mesmo. Autonomia diz respeito à construção de processos de existência a partir das sensibilidades que um corpo cria na experimentação de seus modos de ver, ouvir, tatear e compor com o mundo, produzindo referenciais singulares para si, sob a perspectiva do que é potente ao corpo, do que faz o corpo se expandir. 
No experimentar-sonhar, uma madeira devém-criança, um menino é inventado e se reinventa a seguir.

\section{No 'era uma vez', uma história que começa pelo meio}

$\mathrm{Na}$ oficina organizada, entre balcões e ferramentas, espreita-se o mundo do trabalho. A tomada da cena nos aproxima de um homem no exercício de seu ofício, onde vislumbramos $o$ adulto. Em nossa cultura, dizemos que nos tornamos adultos quando, afeitos a determinados agenciamentos de subjetividade, colamos em valores, características e expectativas oferecidas à priori, plantadas no modelo dominante de nosso tempo. Um devir-criança se faz como resistência a esse modelo: ruptura com as relações de alienação, movimento de abertura a múltiplas conexões e sentidos.

Gepetto, como todo artesão prudente, observa, experimenta, sente, inventa, reinventa, cuida, elabora e sonha, ao se demorar. Mas também se arrisca. Aventura-se em uma jangada em alto-mar e é devorado por uma baleia ao procurar por aquilo que é vida para ele: experimenta em si um devir-criança (Deleuze \& Guattari, 1997) na busca por seu filho. Engana-se, no entanto, quem vê nisso uma surpresa: pois será que não havia ele, enquanto artesão-sonhador, experimentado um devir-criança ao sonhar e brincar com seus sentidos, arriscando um tronco de madeira em "menino de verdade"? Se assim tiver sido, não será a vida, em certa medida, um lançar-se ao mar? Experimentar-se? Aventurar-se, talvez? Ser menino travesso, um pouco?

No embaralho dessas cenas criticadas pela mídia por sua simplicidade, a que temporalidades nos leva uma estória? Que durações de tempo travesso somos capazes de suportar, frente à primazia da seriedade? A que limites estendemos nossos corpos? Por onde, afinal, começa essa fábula? Com um menino de verdade? Um aventureiro escultor? Ou seria um tronco, escolhido ao acaso? Ou um artesão visto sem querer pela fresta de uma janela qualquer em sua cidadela? Era uma vez quem, então? Um corpo em movimento? Um devir no tempo? Outros tempos em nós ao conhecermos essa estória?!

Através do filme re-editado por Benigni sobre Pinocchio, conhecemos, sob outra perspectiva, um marceneiro tornando possível a criação de um menino em meio ao movimento de vida disparado pela possibilidade de sonhar: eis o processo que acontece a Gepetto, criando em si um corpo artesão no momento em que cria seu menino. Um movimento então, de dois corpos criados nas brechas do sonho, abrindo, ainda, brechas para que se torne real o sonhável/ impossível. 
O artesão-sonhador concebe sua obra e concebe vida. Conceber é da ordem do pensar. Pensar intempestivo, que se descola da razão, pensar que assola, des-forma para reformar em outro. Conceber é, neste sentido, elaborar, tomar o real em suas virtualizações, torcer os fatos, duvidar, (re) aprender a olhar e a sentir. Constituição de um plano de consistência, plano de imanência do desejo, "ali onde o desejo se define como processo de produção, sem referência a qualquer instância exterior, falta que viria a torná-lo oco, prazer que viria a preenchê-lo" (Deleuze,1996, p. 15).

No encontro inusitado entre as mãos e um pedaço de tronco, surgem dois novos corpos que despertam e se recriam em meio à inventividade da própria vida que se inventa. Mas o que seria, pois, tal despertar?

Um corpo que desperta é um corpo que distrai, em si mesmo, aquilo que já sabia. Distrai de si mesmo aquilo que (re) conhece, explorando movimentos e ideias. É um corpo que opera uma distração daquilo que vê de imediato, daquilo que percebe prontamente, daquilo a que se acomoda, daquilo que parece única possibilidade real, constituindo um modo-artista de viver. Um movimento de corpo-desatento, que atenta à possibilidade de tornar o Real em reais possíveis, na afirmação de uma pluralidade em que a vida se faz inacabada e sempre em vias de se fazer (Kastrup, 2004).
Um corpo que desperta dissolve, portanto, o plano tão consistente da Verdade, o que parece indubitável, o que parece passível como realidade intrínseca, como a obviedade que uma forma comporta se a vemos ensimesmada. Dissolve o concreto, dissolve o fato, para dar visibilidade ao que poderá ser, a certo plano de virtualidade e indeterminação. Tece, portanto, mesmo aquilo que ainda não se dá como possibilidade imaginada. Neste sentido, desnuda-se do desejo de apreender o mundo para que possa experimentar outras relações com aquilo que vive, tornando-se, ele mesmo, corpo-extensão: desforma e reforma o que há, criando outras realidades e, ainda, se reinventando nesse processo. Impossível identificar começos e fins: fiquemos com os meios.

Ao modo hegemônico de experienciar a vida, no encontro com os fatos, identifica-se o pertencimento dos objetos e corpos, de tal modo que sejam criadas representações mentais, verbais, imagéticas. Transforma-se tudo em palpável e racionalizável, explicando e medindo sentidos, buscando e corrigindo incoerências. Habitando este mundo, o Sonho parece se opor à Verdade, como se fosse mera ilusão.

Pois então, elucidando a aposta contrária a essa antítese, é na persistência do artista que pode o sonhador-artesão afirmar certa dimensão virtual da existência. Desa- 
fia, irrompe à luz de inusitadas criações e desconfigura os fatos dando lugar ao improvável, meio pelo qual a vida se continua.

Poderíamos, inspirados pelo sonhar de Gepetto e atravessados por um modo-criança próprio à interpretação de Benigni, habitar um espaço de passagem entre o sonho, como invenção, e o real, como dimensão dos possíveis. O feitio do sonho como fio de movimento para a transformação. Neste sentido, tratar-se-ia de criar em nós um novo corpo frente aos acontecimentos: um corpo que desperte em si mesmo certo grau de inventividade que lhe permita acolher o tempo em sua intempestividade. Movimentos-devires experimentados não como imitações de certo estado de coisas, mas como passagens de fluxos intensivos instauradores de temporalidades outras, diferentes daquela que a cronologia impõe (Deleuze \& Guattari, 1997). O tempo do artesão, que se entrega a talhar com minúcia e, por vezes, desespero. O tempo do sonhador que cruza passado, presente e futuro, atualizando e reabrindo sentidos em sua experiência. O tempo da criança que se deixa contagiar pela entrega, que se mistura ao que cria e explora desconexões, desdobrando sentidos para si.

Era uma vez o artesão, o sonhador, a criança, o artista em nós.

\section{Habitar a escola - entre os descompassos travessos de "meninos de verdade"}

A escola tem uma única entrada. No portão estreito, pintado de azul, um corte retangular no alumínio nos faz ver o interior: um imenso pátio com edificações nas suas laterais e poucos alunos dispersos, abrigados nas sombras de arbustos. Uma visão que é rapidamente interceptada por corpos que se movem, do outro lado, bem junto ao portão. No vozerio dos jovens, captamos uma voz mais enérgica a repetir normas, quebrar argumentos e desviar solicitações. O portão é aberto lentamente, autorizando a nossa entrada. A figura imensa de um inspetor sentado faz mais difícil o acesso, exigindo um passo a passo e movimentos contidos, até ganharmos o chão da escola.

No caminho que nos leva do pátio à sala de reuniões, outros inspetores, murais meticulosamente organizados, paredes e móveis cuidados; tudo parece ter um lugar. O livro de registros está sobre a grande mesa ao lado de uma pilha de folhas que logo seria passada para nossas mãos. As folhas trazem impressas listas intermináveis de alunos que apresentam algum tipo de dificuldade, tornada necessidade de encaminhamento. Novo vozerio nos coloca em alerta e nos convoca a entrar em cena demandando avaliações de comportamentos e caminhos para a correção de trajetórias. 
As inúmeras interrupções vêm da porta de acesso ao corredor e trazem até nós ecos da burocracia: avisos sobre professores faltosos, cobrança de formulários, procura de processos, assinatura de ocorrências.

$\mathrm{Na}$ circulação pelas salas, nas caminhadas pelos corredores e no retorno ao grande pátio, alguns movimentos arrastam o pensamento com outras intensidades, desalojando um mal estar paralisante. A produção de fracassos encontraria ali pontos de ruptura e descontinuidades? Entre crianças dançantes, funcionários astuciosos, jovens em solidariedades dissidentes, inquietações e descobertas de professores, arriscamos sustentar um campo de indagação.

Em meio a inúmeras queixas, manter os sentidos aguçados na busca das forças que, a um só golpe, movimentam papéis e fixam corpos, se constitui num verdadeiro desafio.

Os ecos da escola disciplinar fazem nossa entrada na escola num tempo lento, espacializado e mecânico, que investe as forças de reprodução desenhando territórios fechados. Cortando esse modo de produção da escola, hoje vinculado à tradição, outro modo de produção ganha consistência sustentado no consenso e na permanente captura, sob a forma de dispositivos de inclusão. O tempo de aceleração produtivista anuncia o esgotamento da 'velha' escola, operando destituições cotidianas de códigos, lugares Rev. Polis e Psique, 2013; 3(2):97-112 e funções, enquanto anuncia um novo regime de dominação (Deleuze, 1992; Passetti, 2007).

A longa duração da disciplina e o curto prazo do controle se materializam em imagens cênicas que, remetidas a representações, parecem estabelecer as condições atuais nas quais se desdobram nossas práticas:

A Fada Azul repara por entre as janelas dessa escola. Observa, cautelosamente, aquilo que acontece por entre os muros altos que circundam o pátio. Aqui e ali queixas sobre violências, desobediências e dificuldades de aprendizagem. Rebeldes, vadios, folgados: alunos que parecem não querer nada, que parecem não aprender nada, alunos em quem não se pode confiar. A Fada Azul escuta e observa, convocada a interferir. O Grilo Falante também passeia por aqui, acompanhando os meninos e meninas em seus acertos e supostas errâncias, atento aos efeitos de suas atitudes. As imagens cênicas, Grilo e Fada Azul, são como pontos de alerta a ecoar para os alunos, para a escola em seu funcionamento e para nós, profissionais que se encontram com a educação...

Ao circular pela escola, como psicólogos, encontramo-nos com narrativas sobre meninos e meninas incapazes, preguiçosos e desatentos. Em meio às desconfianças e estigmas, o espaço escolar se transforma na barriga de uma grande baleia que parece de- 
vorar certos modos de existência e de liberdade, forjando a possibilidade de, tanto os alunos quanto os especialistas convocados, se fixarem às avaliações categóricas. Cercados por tantos julgamentos e urgências inerentes à lógica dominante da produtividade, alguns estudantes não se enquadram a um ideal de aprendiz e, ao se expressarem conforme seus referenciais, desviam (Aguiar \& Monteiro Silva, 2012). Enquanto isso, especialistas preocupados em solucionar os problemas escolares a partir de seus saberes, hegemonicamente reafirmam diagnósticos e determinismos sociais, reproduzindo as condições de produção de fracassos. Tais movimentos aparecem como fortes tendências frente ao desconhecido, às misturas que se animam nesse processamento do devorar.

Como profissionais convocados a atuar na escola sobre os desafios que se tecem junto aos meninos e meninas, preocupa-nos pensar o que nossas práticas vêm produzindo e repensar aquilo que queremos fortalecer. Interessam-nos os tais desvios, pois, por interrogarem elementos tornados naturais e intrínsecos às relações sociais e educativas, enrijecidos, deixam passar outros processos potentes que se inventam por entre as brechas do que se hegemoniza. Como intervir em meio às brechas, então?! Para que lugares nos deslocamos, quando adentramos e nos misturamos com as narrativas que, numa escola, nos convoca a parRev. Polis e Psique, 2013;3(2):97-112 ticipar? Alguma possibilidade de agenciar os cuidados do Grilo aos cuidados da Fada, dissolvendo, na barriga da baleia, a dureza da moral e a solução mágica dos desafios que um território escolar nos coloca? Que entrada para uma Psicologia que dispara, no encontro com a estória de Pinocchio, reflexões éticas sobre sua própria prática?

Indagando-nos por estas vias, colocamos em análise a formulação das queixas escolares, liberando as culpas que paralisam e embotam o pensar inventivo. Dobramo-nos, ainda, sobre nós mesmos interrogando nossas implicações com as instituições que se atualizam nos processos de trabalho na escola, as práticas e enunciados que afirmamos e seus efeitos em nossos corpos. Consideramos, como campos de análise e de intervenção, nossos próprios encargos sociais que historicamente aparecem aliados à lógica de constrangimento das forças de expansão da vida, fornecendo subsídios técnicos e argumentos teóricos para estratégias de normalização e de individualização. Tais estratégias, apoiadas na dissociação entre as dimensões sócio-políticas e a subjetividade, classificam como desvio qualquer fuga dos padrões estabelecidos e indicam a intervenção necessária na criança, na professora, na família, todas culpabilizadas (Aguiar \& Monteiro Silva, 2012).

Em meio aos ecos e cuidando daquilo que deles nos atravessa, entendemos 
que intervir não é um processo individual e uni-direcionado, aplicação de um campo de saber sobre seu objeto. Por isso, experimentando em nós também um modo artesão, como Gepetto, sustentamo-nos na construção de um plano comum com o corpo da escola e com os próprios estudantes sobre quem se narra, apostando na composição de olhares entre os diversos discursos e enunciados que tecem alunos-problema, avaliando pensamentos e práticas entre o existente e a criação de possíveis (Aguiar \& Monteiro Silva 2012).

Um projeto comum tem sua função "mais como um reservatório compartilhado, feito de multiplicidade e singularidade, do que como uma unidade atual compartida" (Pélbart 2008, p. 4). Neste sentido, contemplamos a dimensão da diferença nos processos de escolarização, apostando nas forças que nos fazem diferir do que somos, em meio às travessuras e desassossegos dos corpos. É exercitando este olhar que podemos interceder provocando novos encontros entre práticas educativas e meninos travessos, ao fortalecer o que já se apresenta como potência ali mesmo, no território escolar ou 'na barriga da baleia', onde à primeira vista se vê desespero, mas há um mundo de infinitos elementos virtuais, disponíveis à combinação e atualização, produzindo resistências.
No entanto, cabe uma ressalva: embora investindo na construção de relações de proximidade com os meninos e meninas travessos de quem falamos, apostando nos processos criativos e autônomos que se criam nas brechas de suas irreverências, não podemos deixar de considerar as forças moralizantes que atravessam nossa própria prática e as práticas educativas. É nesse sentido, de uma certa prudência aliada ao risco, que também afirmamos o humor em sua potência disruptiva, contagiante; atentas à sua modulação reacionária que pode favorecer o escárnio e a humilhação.

$\mathrm{Na}$ aula da professora Valmira, os alunos gritam sem parar. Uma menina, Lia, elogia seu sapato. A professora mal sorri, cansada e interpelada se havia tom de ironia ou se o elogio era sincero. A professora Valmira ensina matemática. As crianças compram doces e contam trocos na lanchonete no horário do recreio, mas não sabem calcular números em papel. Dizem ser "um saco!", impacientes pelo toque do sinal. João se sente burro e fica mudo quando erra uma pergunta em sala de aula. Mas João é tagarela. A professora Valmira já reclamou muito, hoje só respira duas vezes antes de pedir atenção. Um grupo de cinco meninos e meninas da turma, ouvindo o erro de João, cantarola músicas e chama-o de burro, em coro desafinado. João levanta, dança e desafia a resposta certa. A turma fica muda. 
João ri e canta. Agora, também em silêncio, se empenha em reproduzir cenas que envolvem a professora e seus alunos no exercício da conta certa, da boa resposta, do comportamento correto. Reproduz intensificando, tal qual nas caricaturas, pequenos gestos, expressões e reações que caracterizam cada um. Alguns se desacomodam nas cadeiras, Valmira levanta a sobrancelha em tom de surpresa; entre sorrisos e risos, alguns arriscam a adivinhar quem se atualiza na performance de João. Uma atmosfera de ansiedade, uma certa tensão, toma conta de nós. $\mathrm{Na}$ aceleração das intervenções, dos nomes próprios adjetivados - Zulmira burra, Maurílio chato, Silas vadio, Iara besta - passam aos verbos: errando! saindo! gritando! repetindo! acertando! mentindo! gostando! brigando!. Movimentos de despersonalização a oferecer fissuras às formas, desvios dos bons procedimentos, risos sobre nós mesmos e, a depender dos agenciamentos, aberturas a outros possíveis. Mas isto é uma outra estória...

\section{Referências}

Aguiar, K.F.(2003). Ligações perigosas e alianças insurgentes - subjetividades e movimentos urbanos. Tese de Doutorado. Curso de PósGradauação em Psicologia Social,
Pontifícia Universidade Católica de São Paulo, São Paulo.

Aguiar, K.F. \& Monteiro Silva, V. (2012). Das queixas aos problemas escolares - $\mathrm{o}$ plantão institucional como dispositivo. Em: IV Congresso Internacional Cotidiano: Diálogos Sobre Diálogos, $\mathrm{n}^{\mathrm{o}} 1$. Niterói. Anais do IV Congresso Internacional Cotidiano: Diálogos sobre Diálogos, Niterói:Faculdade de Educação/UFF. CD.

Bakhtin,M.(1996) A cultura popular na idade média e no renascimento. O contexto de François Rabelais. Brasília/São Paulo:EdUNB/Hucitec. Benigni,B.;Braschi,G.; Braschi,N. (2002)

Pinocchio. [Filme] Produção de Gianluigi Braschi e Nicoletta Braschi, direção de Roberto Benigni. Itália/EUA.

Deleuze, G. (1982). Lógica do Sentido. São Paulo: Editora Perspectiva.

Deleuze,G.(1992). Conversações. Tradução

Peter Pál Pelbart. Rio de Janeiro: Editora 34.

Deleuze,G.(1996). Lo que dicen los niños. Em Deleuze,G., Crítica y clínica (pp.89-97). Barcelona:Editorial Anagrama, 1996, p.87-97. 
Deleuze,G. (2002). Imanência: uma vida... Educação \& Realidade, Porto Alegre, v. 2, n. 2, 10-17, jul./dez.

Deleuze,G \& Guattari,F.(1996). Mil Platôs - Capitalismo e Esquizofrenia. Vol. 3; coord. de tradução Ana Lúcia de Oliveira - Rio de Janeiro: Editora 34. (Coleção TRANS).

Deleuze,G \& Guattari,F.(1997). Mil platôs - capitalismo e esquizofrenia. vol. 4; tradução de Suely Rolnik. - Rio de Janeiro: Ed. 34. (Coleção TRANS).

Deleuze,G \& Guattari,F.(2007). O que é a Filosofia?. Tradução Bento Prado Jr. e Alberto Alonso Munhoz. Rio de Janeiro: Ed. 34.

Fonseca,T.M.G. \& Thomazoni, A.R.(2011). Obra de Arte como Território de Existência. Fractal: Revista de Psicologia, v. 23, n. 3, 523-534, set/ dez.

Foucault,M.(2000). O que são as luzes? Em Motta, M.B.(Org.), Ditos e Escritos II - Arqueologia das Ciências e História dos Sistemas de Pensamento(p.335-351). Rio de Janeiro: Forense Universitária.

Guattari, F. (1981). Devir criança, malandro, bicha. Em Guattari, F., Revolução molecular: pulsações políticas do desejo (pp.64-69) Tradução Suely Rolnik. $1^{\text {a }}$ ed. São Paulo: Editora Brasiliense.
Guattari, F. \& Rolnik,S. (1986). Micropoliticas, Cartografias do Desejo. Petrópolis: Vozes.

Gil,J. (2000). O Corpo bailarino. Revista Contracampo (Pós-Graduação em Comunicação da UFF), nº5, Niterói, 07-19, segundo semestre.

Kastrup,V.(2004). A aprendizagem da atenção na cognição inventiva. Psicologia \& Sociedade, 16 (3), 7-16, set./dez.

Lévy,P.(1996). O que é o virtual?. São Paulo:Ed.34.

Morrin,V.(1976). Historieta Cômica. Em Análise Estrutural da Narrativa: pesquisas semiológicas. Petrópolis: Vozes, 174-200.

Passetti, E. (2012) Poder e Anarquia apontamentos libertários sobre o atual conservadorismo moderado. Verve Revista do NU-SOL, $\mathrm{n}^{\circ} 12,11-43$, Outubro/2012.

Pessoa, F. Livro do Desassossego: composto por Bernardo Soares, um ajudante de guarda-livros na cidade de Lisboa. Organização Richard Zenith. São Paulo: Companhia das Letras, 2006. Pelbart, P. P.(2008) Elementos para uma cartografia da grupalidade. Em Saadi, F; Garcia, S. (Orgs.), Próximo ato: Questões da Teatralidade Contemporânea (pp. 33-37).São Paulo: Itaú Cultural. 
Spinoza, B.de. (2008) Ética. Belo Horizonte: Autêntica.

Katia Faria de Aguiar: Prof ${ }^{a}$ Associada do Departa,mento de Psicologia da Universidade Federal Fluminense, vinculada ao Programa de Pós-Graduação em Psicologia, linha de pesquisa Subjetividade, Política e Exclusão Social. Doutora em Psicologia Social PUC/SP e Mestre em Educação - UFF.

E-mail: katiafaguiar@uol.com.br
Vanessa Monteiro Silva:Psicóloga, graduada e mestranda pela Universidade Federal Fluminense. Atua com psicologia clínica e tem experiência de pesquisa e intervenção com crianças e jovens em práticas de formação escolar e artística.

E-mail: vanessams_psi@yahoo.com.br

Recebido em: 06/09/2013 - Aceito em: 11/12/2013 